\title{
Reproduction probabilities and size distributions of the smooth snake Coronella austriaca in the Netherlands and Norway
}

\author{
Domin Dalessi $^{1, *}$, Harm Bolle ${ }^{2}$, Eelke Jongejans ${ }^{1}$, Pål Sørensen ${ }^{3}$, Henk Siepel ${ }^{1,2}$
}

\begin{abstract}
Whether females participate in reproduction every year or rather skip years is pivotal information for understanding the dynamics of animal populations. In ectotherms this reproduction frequency might depend on factors like temperature, individual size, and prey availability. Here we studied the reproduction rate of the smooth snake Coronella austriaca at two latitudes: in Norway and The Netherlands. Reproductive and morphological data were collected in Norway (34 years) and The Netherlands ( 5 years). To account for differential resighting probabilities of pregnant and non-pregnant females, we performed multi-state mark-recapture analyses. Reproductive rate, quantified as the probability of participating in reproduction in consecutive years, was calculated for both pregnant and non-pregnant females. The results showed a clear difference in reproductive rate between the two latitudes, with only $15 \%$ of pregnant females reproducing again in the following year in Norway versus 93\% in The Netherlands. Furthermore, in Norway females grew larger and started reproduction at a higher age. Litter size and juvenile total length and body mass were also significantly higher in Norwegian smooth snakes.
\end{abstract}

Keywords: Cormack-Jolly-Seber, Coronella austriaca, multi-state model, reproductive rate, South Norway, southeastern Netherlands.

\section{Introduction}

Whether individuals can reproduce every year or not is a key vital rate for animal population dynamics (Prival and Schroff, 2012). For ectotherms like reptiles, the reproduction probability might depend on temperature, food availability, and individual size (Scharf et al., 2015; Hileman et al., 2017). Breeding success is determined by energy stored and prey availability, among many other factors (Lourdais et al., 2002). Annual mean temperature can also affect reproductive output, for instance mild winter conditions can induce an increase in body condition, and consequently higher reproduction rates (Brischoux et al., 2016). These temperature effects on ectotherms also lead to the

1 - Institute for Water and Wetland Research, Animal Ecology and Physiology, Radboud University, Heyendaalseweg 135, 6525 AJ Nijmegen, The Netherlands

2 - Plant Ecology and Nature Conservation Group, Wageningen University, PO Box 47, 6700 AA Wageningen, The Netherlands

3 - Bodøgata 2, 0565 Oslo, Norway

*Corresponding author;

e-mail: D.Dalessi@onsbrabantnet.nl expectation that individual reproduction probabilities change over latitudinal or altitudinal gradients due to changes in temperature throughout the reproductive season: when summer seasons become shorter (e.g., pole-wards or at higher altitudes), reproduction could be expected to become less frequent, while energy maybe spent more on an increase of body mass (Buckley et al., 2012; Rutschmann et al., 2020; Verberk et al., 2020).

Here we focus on the reproduction rate of the smooth snake Coronella austriaca (Laurenti, 1768). Reproduction rate is linked to an increased allocation of resources into reproduction as growth decreases with age/size, but reproductive output also varies among individuals (Luiselli et al., 1996; Stahlschmidt et al., 2013). Maturity is reached at 4 to 5 years for females, depending on where animals were studied (Creemers and van Delft, 2009). The frequency of reproduction in smooth snakes has been a topic of debate over the past decades. Reproduction frequencies have been determined in various ways, often based on grey literature, expert opinion, by determining 
observed proportions of females that are pregnant, or short-term records of marked individuals (Goddard and Spellerberg, 1980), usually focusing on annual, biennial or triennial reproductive cycles. For instance, in central Italy and central France, an annual cycle was mentioned by Capula et al. (1995), Fretey (1975), and Duguy (1961). Völkl and Käsewieter (2003) mention a biennial reproductive cycle (i.e., with one non-reproductive year between reproduction events) for central Europe, as did Goddard and Spellerberg (1980) and Monney et al. (1995). A biennial cycle is also suggested for The Netherlands, based on field observations between 1976 and 1986 by Strijbosch and van Gelder (1993). For Scandinavian populations a bi- to triennial reproductive cycle is indicated by Andrén and Nilson (1976) and Sørensen (2014). Direct observations of reproductive cycles were made by Luiselli et al. (1996) who monitored several females for up to 5 years in the Italian Alps (at $1100 \mathrm{~m}$ altitude) and found 1 annual reproductive cycle, 4 biennial and 1 triennial cycle. The time span of that study, however, was too short to detect longer cycles.

Although some patterns emerge from these sources, large uncertainty remains on the duration of the reproductive cycle due to the anecdotal nature of several of these records, or due to the biases towards observing shorter cycles in short-term studies. Furthermore, as Luiselli et al. (1996) mention, reproductive females change their behaviour by basking more than non-reproductive females. This means that reproductive females are more easily observed, which potentially leads to further biases in analyses of reproductive cycles. These shortcomings clearly indicate that to properly estimate reproductive probabilities of smooth snakes, capturemark-recapture (CMR) analyses are required. Specifically, two-state models should be deployed to allow for contrasting resighting probabilities for reproductive and non-reproductive females, and to estimate subsequent year's reproductive probabilities depending on whether a female is reproductive in the current year or not.

Here we present CMR data and two-state model analyses for smooth snake populations in The Netherlands (during a five-year period) and Norway (over 30 years). We expected that reproductive probabilities increased with snake size and are influenced by annual temperature, among other factors resulting from differences in both latitude and altitude between The Netherlands and Southern Norway. Also, we expected biennial cycles in The Netherlands (Strijbosch and van Gelder, 1993), and bi- to triennial cycles in Norway (Andrén and Nilson, 1976; Sørensen, 2014). Finally, we discuss the importance of latitudinal differences in snake sizes and reproductive cycle lengths with respect to costs of reproduction and population dynamics.

\section{Materials and methods}

\section{Study areas and climate}

According to the Köppen climate classification the Eindhoven area in The Netherlands $\left(51^{\circ} 27^{\prime} 0^{\prime \prime} \mathrm{N}, 5^{\circ} 28^{\prime} 0^{\prime \prime} \mathrm{E}\right)$, has a $\mathrm{Cfb}$ type climate (marine west coast climate), with an annual mean temperature of $9 .{ }^{\circ} \mathrm{C}$, and $17.2^{\circ} \mathrm{C}$ on average during the warmest month. Average temperature during the coldest month is $2.2^{\circ} \mathrm{C}$ (Peel et al., 2007). The Oslo area $\left(59^{\circ} 54^{\prime} 41^{\prime \prime} \mathrm{N}, 10^{\circ} 45^{\prime} 29^{\prime \prime} \mathrm{E}\right)$ on the other hand has a Dfb type climate (warm summer continental climate; annual mean of $6.7^{\circ} \mathrm{C}, 18^{\circ} \mathrm{C}$ during the warmest month, $-3^{\circ} \mathrm{C}$ during the coldest month; Peel et al., 2007).

In The Netherlands the study area consists of a number of remaining nature fragments of De Peel, a once large moorland area in the South-east of The Netherlands (NL, fig. 1)). Fragmentation is largely due to peat extraction and transformation of the former peat bog into farmland. De Peel is located across and along the border of the provinces NoordBrabant and Limburg. Two large and a number of smaller geographical elements can be distinguished that still show most of the original natural conditions and features of a peat-bog moor. De Groote Peel (1500 ha; a national park) is one of these, the other is a combined area consisting of the Deurnsche Peel (1400 ha) and the adjacent Mariapeel (1400 ha). The vegetation in these sites is dominated by Purple moor-grass (Molinea caerulea). Other plants species that are mainly found are common heather (Calluna vulgaris), cross-leaved heath (Erica tetralix), small trees and different species of peat moss (Sphagnum spp.). In this study we included six locations within these two nature Downloaded from Brill.com04/26/2023 05:23:11AM 


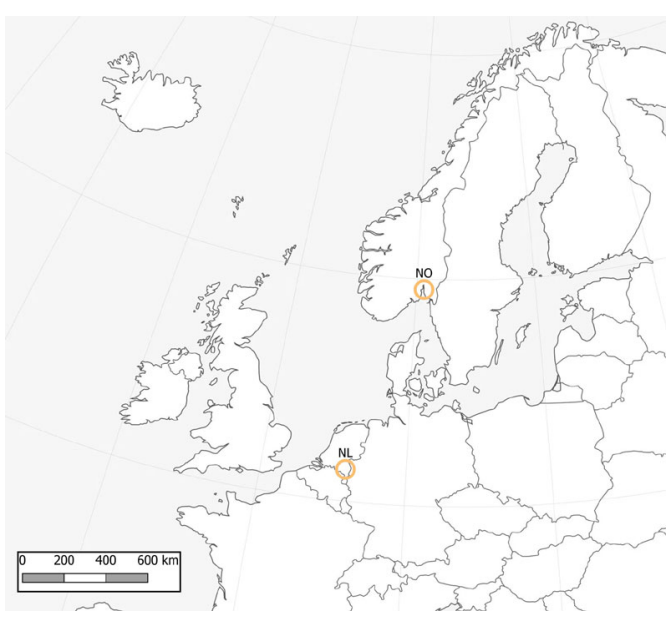

Figure 1. Map showing both research location in The Netherlands (NL) and Norway (NO).

reserves: Groote Peel Yellow track (GG), Groote Peel summer biotope (GZ), Groote Peel Noordoostpad (NO), Mariapeel East (ME), and in the Deurnsche Peel: Leegveld (LV) and Eikenlaan (EL).

In the South of Norway (NO, fig. 1), Coronella austriaca is found mainly in a narrow area along the southwestern coastline. Typical habitat is more or less isolated open areas (surrounded by forest varying in density) with south-facing rocky slopes. Patches of small trees and shrubs are present in these areas and particularly crevices and parts where cracks filled with plant material, loose rocks and stones occur, are the spots where smooth snakes were found. Typical plant species are Scotch pine (Pinus silvestris), juniper (Juniperus communis) and birch (Betula verrucosa). Heather (Calluna vulgaris) is dominating the lower vegetation (Sørensen, 2014). This study includes data from 8 different locations (mainly fjord-related habitats) south of Oslo (Sørensen, 2014): Pollevannet, Skjelvik, Emmerstad, Bunnefjorden, Eineåsen, Digerud, Tofte and Bleikslitjern.

\section{Field observations and data collection}

In The Netherlands we searched for smooth snakes during their reproductive season (April/May to August/September) from 2011 until 2015. Visiting frequencies were higher from 2012 onwards (ranging from approximately 40 visits in 2011,60 visits in 2012, 80 visits in 2013 to around 130 visits during 2014 and 150 visits during 2015, for at least once a week in all years), and were higher in LV and ME than in the other areas. Observations in Norway were collected with frequencies varying from 1 to 20 visits per year varying with weather conditions and available time.

In The Netherlands, a total of 110 distinguished individual female snakes were included in the analysis. A number of these individuals were observed during multiple years, adding up to a total of 157 observations, 142 of which involved pregnant females and 9 observations non-pregnant females. In 6 cases the pregnancy status was not established with certainty.
Females were determined to be pregnant or non-pregnant visually (in many cases the unborn snakes can readily be observed) or by means of palpating in both Norway and The Netherlands (Reading, 2004a). We assumed that a more or less constant group of pregnant females resided in the same area during the reproductive season (Bonnet and Naulleau, 1996; Reading, 2012). Observations on individual males, which probably mature somewhat earlier (Naulleau, 1987), were both left-truncated (unknown ages) and right-censored (unknown deaths).

The exact location of each snake found was determined and recorded by using a GPS device (Garmin eTrex 10, accuracy $3 \mathrm{~m}$, RD coordinates). Physical traits such as sex, total body length (depicted as SVL (snout-vent length) and tail length (TL) (measured with measuring tape (cm)) were recorded. We used total body length in our analyses (SVL + TL). Body mass was determined by use of a scale-beam (Super Samson, $200 \mathrm{~g}$ max., increments $2 \mathrm{~g}$ ), also weather conditions (rain, sun, clouds, wind $(\mathrm{km} / \mathrm{h})$, air temperature), and other striking and specific characteristics (for example artificial hide, path, tree trunks, roadsides etc.) of the habitat were occasionally recorded. Photographs of the heads of all snakes (from above) and first 5-15 centimetres of dorsal side of the body were taken in order to be able to distinguish individual snakes, based on colouration and markings present on the skin (Sauer, 1994). Each individual was marked with a small dot of green nail polish on the head and thereafter released at the exact same spot where it was captured. This was done to prevent the same individual to be handled more than necessary during the season (at least until the next shedding of skin when the mark was lost). Permits (Flora- en Faunawet; FF/75A/2011/012, FF/75A/2014/053 and $\mathrm{FF} / 75 \mathrm{~A} / 2016 / 015)$ were issued by the government of The Netherlands. The Animal Experiments Commission of the Radboud University approved this research (RU-DEC 2013-064), while State Forestry (SBB) permitted fieldwork in their nature reserves.

In Norway, measurements of participation in reproduction of female snakes were carried out during a varying number of consecutive years between 1982 and 2015. Generally, more observations were made per individual, but for fewer individuals than in The Netherlands. Exact locations of the found individuals were determined and measurements such as length (i.e., total body length (SVL $+\mathrm{TL}$ ), body mass and whether females were pregnant or not were taken using the same methods as in The Netherlands. Individual females were photographed in order to distinguish between individuals according to the same protocol used in The Netherlands.

A total of 87 distinguished individual female snakes from Norway were included in the analysis. A number of these snakes were observed during multiple years, adding up to a total of 184 observations, 148 of which were determined pregnant, and 29 observations were determined nonpregnant. In 7 cases pregnancy status was not established with certainty. 


\section{Food preferences}

The main food sources in Norway are shrews (Sorex spp.) and slow worms (Anguis fragilis) (Sørensen, 2014). In The Netherlands food preferences consist predominantly of reptiles and small mammals as well, however not necessarily the same species. Exact food preferences for De Peel are still under investigation. Although it is widely accepted that reptiles constitute a large part of the food taken (Reading and Jofré, 2013), the only other reptile species present in De Peel is the common lizard Zootoca vivipara, albeit in low densities. Therefore, small mammals probably constitute the remainder of the diet.

\section{Important microclimate features}

Preferred body temperature of the smooth snake seems to lie around $30^{\circ} \mathrm{C}$ (Creemers and van Delft, 2009; Völkl et al., 2017). Variation in temperature is an important feature of the habitat of the species. Smooth snakes tend to hide and often extract warmth from the surrounding substrate and vegetation. In De Peel vertical variation (edges, slopes, elevations etc.) induces variation in temperature and humidity conditions. Although smooth snakes were found under various conditions the availability of dry spots as well as humid surroundings (for example for snakes about to shed their skin) are of importance. In Norway crevices in the rocky soil as well as tilted surfaces provide a large range of microclimatological opportunities for the animals to choose from.

Since the number of observations appeared to increase quickly above certain temperatures, we searched for a particular temperature threshold. By determining minimally required temperatures and the required duration of warm spells in Spring, we aimed to determine major climatological differences between the two study sites.

\section{Statistical analysis}

In Norway, pregnancy status could be determined in most cases throughout the entire season since female smooth snakes are much larger, therefore it is easier to determine pregnancy. Therefore, all observations were included. However, for the snakes in The Netherlands pregnancy status was only derived from data between mid-June and the end of August. Within this time frame, it was possible to determine with certainty whether a particular female was pregnant or not. The program MARK (version 8.1) was used for Cormack-Jolly-Seber and two-state capture-mark-recapture analyses (Jolly, 1965; Seber, 1965; Joe and Pollock, 2002; Lebreton and Pradel, 2002). As the pregnancy status was sometimes uncertain (6 times in The Netherlands, 7 times in Norway), the datasets were analysed twice: first including uncertain observations as non-pregnant females and in a second run including them as pregnant females (illustrating variation/spread/uncertainty of the results).

To quantify both the observation and reproduction processes, we fitted models that included state-specific (pregnant vs non-pregnant) recapture (p) and survival $(\varphi)$ probabilities. Estimates of transitions between the two states quantified the likelihood of consecutive years of reproduction.
The effort invested in searching logically affects the probability of finding a particular snake. Year-specific observation effort was therefore included in the analyses as a covariate (Schwarz and Arnason, 1996), but this information was only available for The Netherlands.

Goodness of fit (GOF) testing was used to test if the model complied with the underlying assumptions of the model, and was performed in the program RELEASE or UCARE. The tests produced a $\hat{c}$-value, which is an indication of the "lack of fit" for the most parameterized model, being ideal when its value is 1 . Model selection was performed after GOF-testing and was based on the AICc (the corrected Akaike information criterion for small populations). Models were ranked based on the AICc. When the values for different models were very similar a likelihood ratio test (LRT) was performed to analyse if models differed significantly. A correct estimate of the parameters involved is very important. When estimates were very unlikely or confidence intervals were very large, the most parsimonious model was chosen.

\section{Results}

\section{Climatological characteristics}

Based on ambient air-temperature data collected in De Peel during a 9-year period (2011 to 2019) over $93.5 \%$ of all observations $(n=$ 830) were recorded at $15^{\circ} \mathrm{C}$ or higher (fig. 2). This steep increase of visual observations during the start of the season is also mentioned by other authors (Köntopp, 2010; Völkl et al., 2017). Thus, we calculate the length of the season for both Norway and The Netherlands as the number of days having a temperature higher than $15^{\circ} \mathrm{C}$. The active season for smooth snakes is therefore estimated to start during the first half of May in the Oslo area, since a temperature of $15^{\circ} \mathrm{C}$ is becoming more and more common. Halfway September the $15^{\circ} \mathrm{C}$ threshold is rarely observed assuming the end of the active season for smooth snakes in Norway. The mean number of days where air temperatures reached/exceeded $15^{\circ} \mathrm{C}$ was 139.9 days for Norway, based on an 11-year average (2007-2017; https://klimaservicesenter.no/observations/).

The active season for smooth snake in The Netherlands ranges from approximately March to October. When looking at the occurrence of the $15^{\circ} \mathrm{C}$ threshold in the Eindhoven area 


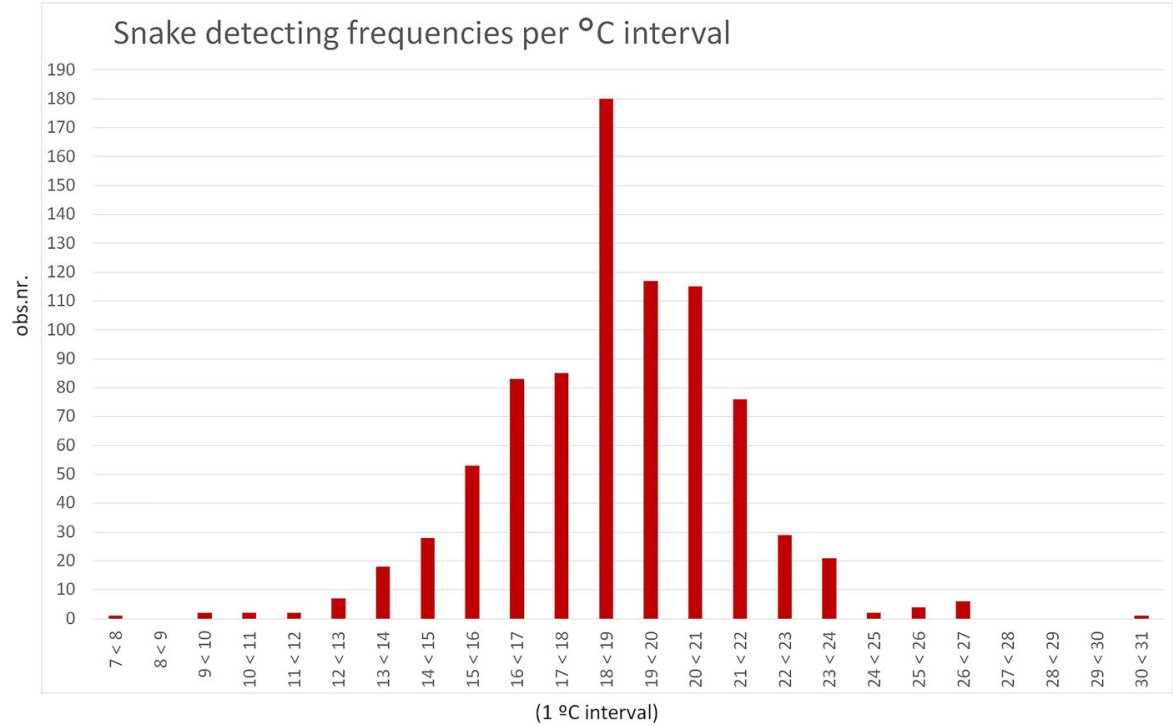

Figure 2. Correlation of ambient temperature and number of observations $(n=830)$.

the onset of the active season is approximately during the second half of March and this temperature threshold is prevailing until the second half of October. The annual number of days with temperatures reaching $15^{\circ} \mathrm{C}$ or more were again determined for an 11-year period (2007-2017). Mean number of days was 187.8 (https://www.knmi.nl/nederland-nu/ klimatologie/daggegevens). According to these calculations the active season is approximately 48 days $(+34 \%)$ longer in The Netherlands compared to Norway.

\section{Mark-recapture data and reproductive frequency estimation}

Goodness of Fit testing for the Dutch population of snakes was performed with the most complex model, having time dependence on recapture and survival probability. The RELEASE program was used for the recapture data and yielded a $\hat{c}$ of $0.236\left(X^{2}=1.65, \mathrm{Df}=7, p=\right.$ $0.98)$ implying underdispersion. For underdispersion a correction is not needed (Cooch and White, 2019).

For the Dutch population of smooth snake, the most parsimonious CJS model was the one without time-discrimination for survival
Table 1. Models run for a Cormack-Jolly-Seber analysis for survival and recapture of $C$. austriaca in the Netherlands and Norway. The most parsimonious models are the ones without time dependence in survival (Phi) and resighting $(p)$ estimates.

\begin{tabular}{lcccc}
\hline Model & AICc & $\begin{array}{c}\text { AICc } \\
\text { weight }\end{array}$ & $\begin{array}{l}\text { Number of } \\
\text { parameters }\end{array}$ & Deviance \\
\hline \multicolumn{5}{c}{ The Netherlands } \\
Phi $(\cdot) p(\cdot)$ & 222.86 & 0.429 & 2 & 26.60 \\
$\operatorname{Phi}(\cdot) p(t)$ & 223.55 & 0.303 & 5 & 20.85 \\
$\operatorname{Phi}(t) p(t)$ & 224.51 & 0.212 & 7 & 17.31 \\
$\operatorname{Phi}(t) p(\cdot)$ & 226.20 & 0.080 & 5 & 23.50 \\
& & Norway & & \\
$\operatorname{Phi}(\cdot) p(\cdot)$ & 505.15 & 1.000 & 2 & 322.03 \\
$\operatorname{Phi}(\cdot) p(t)$ & 528.93 & 0.000 & 34 & 264.50 \\
$\operatorname{Phi}(t) p(\cdot)$ & 562.04 & 0.000 & 33 & 300.73 \\
$\operatorname{Phi}(t) p(t)$ & 609.20 & 0.000 & 60 & 244.20 \\
\hline
\end{tabular}

and recapture probabilities. Other models had higher AICc (table 1). The two best fitting models $(\operatorname{Phi}(\cdot) p(\cdot)$ and Phi $(\cdot) p(t))$ did not differ significantly $\left(X^{2}=5.75, N=2, p=0.1244\right)$, however, the first model needed fewer parameters to estimate survival and recapture and was therefore chosen. The survival probability, not discriminating for pregnancy and time (i.e., there was one estimate applicable to all 4 recapture occasions) was estimated at 0.73 (95\% confidence interval, 0.56-0.85). Recapture proba- 
bility was estimated to be $0.38(0.25-0.53)$. The characteristics of all models can be found in table 1.

For the Norwegian population Goodness of Fit testing was performed with the most parameterized model using the RELEASE program. It yielded a $\hat{c}$ of $0.353\left(X^{2}=16.6, \mathrm{Df}=47\right.$, $p=1.0)$ also implying underdispersion.

Survival analysis of the Norwegian data also showed that the CJS model without time dependency in either parameter was the most parsimonious model (table 1). All other models showed a higher AICc. Survival from one year to the following (for the 30-year sampling period) was estimated at 0.83 (0.77-0.87). Recapture probability was estimated at $0.32(0.25-0.39)$.

The reproductive rate of the smooth snake was determined by calculating the change of state, i.e., the pregnant or non-pregnant states, in a multi-state model (MSM). For the Dutch snakes, the most parsimonious model selected was the one with state dependency in all three parameters (parameters being survival, recapture and movement; table 2).

The probability of a pregnant female becoming pregnant again in consecutive years was 0.90 (0.43-0.99) (graphically summarized in fig. 3). Goodness of fit was performed using a U-CARE program. This resulted in a $\hat{c}$ of 0.53
$\left(X^{2}=4.22, \mathrm{Df}=8, p=0.83\right)$ implying underdispersion. Individuals for which the state of pregnancy was uncertain ( 8 observations), were considered non-pregnant in this case. Regarding them as pregnant females gave a probability of 0.96 (0.67-0.99) of becoming pregnant during consecutive years with a $\hat{c}$ of $0.60\left(X^{2}=4.82\right.$, $\mathrm{Df}=8, p=0.77)$. For the latter analysis, the same model proved to be the most parsimonious one as stated in table 2 .

When uncertain observations in Norway were regarded as not pregnant female snakes, the most parsimonious multi-state model also was the $S(g) p(g) \operatorname{Psi}(g)$ model. The $\hat{c}$ was calculated with the U-CARE program and yielded a value of $0.52\left(X^{2}=28.57, \mathrm{Df}=54, p=0.99\right)$. Here the chance of being pregnant in consecutive years was estimated at 0.09 (0.04-0.20). Remarkably, the chances of being pregnant after a year of not participating in reproduction were higher at 0.69 (0.5 0.84) (fig. 3). In the second analysis, where the seven uncertain observations were regarded as pregnant, the chance of being pregnant in consecutive years of course was higher 0.21 (0.11-0.36). The goodness of fit was determined with U-CARE and yielded a $\hat{c}$ of $0.46\left(X^{2}=25.18\right.$, df $\left.=55, p=1.00\right)$. The most parsimonious model in the latter analysis was also $S(g) p(g) \operatorname{Psi}(g)$ (table 2).

Table 2. Most parsimonious models for multi-state estimation in the Netherlands and Norway, conservative (regarding uncertain observations non-pregnant (upper line) and progressive (regarding uncertain observations pregnant, lower line).

\begin{tabular}{|c|c|c|c|c|c|}
\hline Model & $\mathrm{AICc}$ & $\begin{array}{l}\text { Delta } \\
\text { AICc }\end{array}$ & $\begin{array}{c}\text { AICc } \\
\text { weight }\end{array}$ & $\begin{array}{l}\text { Num. } \\
\text { Par. }\end{array}$ & Deviance \\
\hline \multicolumn{6}{|c|}{ The Netherlands } \\
\hline $\begin{array}{l}S(g) p(g) \operatorname{Psi}(g) \\
\quad(\text { uncertain observations seen as non-pregnant) }\end{array}$ & 250.663 & 1.4808 & 0.1204 & 6 & 43.153 \\
\hline $\begin{array}{l}S(g) p(g) \operatorname{Psi}(g) \\
\quad(\text { uncertain observations seen as pregnant) }\end{array}$ & 242.469 & 1.2450 & 0.1324 & 6 & 42.352 \\
\hline \multicolumn{6}{|c|}{ Norway } \\
\hline $\begin{array}{l}S(g) p(g) \operatorname{Psi}(g) \\
\quad \text { (uncertain observations seen as non-pregnant) }\end{array}$ & 587.332 & 0.000 & 0.4278 & 6 & 415.095 \\
\hline $\begin{array}{l}S(g) p(g) \operatorname{Psi}(g) \\
\quad \text { (uncertain observations seen as pregnant) }\end{array}$ & 591.709 & 2.115 & 0.2578 & 6 & 419.472 \\
\hline
\end{tabular}






Figure 3. Changing state estimates between successive years for all states possible for the most conservative (left number) and the most inclusive approach (right number) for smooth snake Coronella austriaca in the Netherlands (a) and Norway (b). Arrow width corresponds to probabilities.

Comparing various features of pregnant females and neonates from De Peel (The Netherlands) and Norway gave highly significant differences. In all cases t-tests were applied and gave values of $P<0.00001$ concerning litter size, total body length and body mass of all groups included (fig. 4). Norwegian smooth snakes have, compared to Dutch ones, on average a larger clutch size (NL: $n=39, \bar{x}=6.13$, S.D. $=2.16$. NO: $n=98, \bar{x}=8.03$, S.D. $=$ 2.21). They produce longer (NL: $n=171$, $\bar{x}=16.79$, S.D. $=1.09$; NO: $n=293, \bar{x}=$ 20.59, S.D. $=1.52$ ) and heavier neonates (NL: $n=171, \bar{x}=1.8$, S.D. $=0.27$; NO: $n=$ $177, \bar{x}=2.96$, S.D. $=0.51)$. Pregnant females in Norway are much heavier compared to the females from The Netherlands (NL: $n=151$, $\bar{x}=64.39$, S.D. $=15.56$; NO: $n=180$, $\bar{x}=116.09$, S.D. $=28.59)$ and also longer (NL: $n=211, \bar{x}=54.68$, S.D. $=4.77$; NO: $n=173, \bar{x}=73.4$, S.D. $=7.38$ ), but reproduce less frequently.

\section{Discussion}

Our capture-mark-recapture analysis showed that the reproduction probabilities of smooth snakes differ considerably between Norway and
The Netherlands. In the latter the overall probability of reproduction was much higher than expected: Strijbosch and van Gelder (1993) and Creemers and van Delft (2009) assumed a two-year reproductive cycle. It should be noted that pregnant female smooth snakes were far more often encountered than non-pregnant individuals (in this study a total of 262 observations of pregnant versus 36 observations of non-pregnant females) simply because they bask more often when pregnant and are therefore easier to spot. Still, our findings translate to a nearly annual reproduction cycle in The Netherlands (including occasional nonreproductive years: $93 \%$ of pregnant and $50 \%$ of non-pregnant females breed during the following year). Female smooth snakes in Norway seem to follow a different reproduction pattern: the probability of females reproducing in consecutive years in Norway is low (15\%). Non-pregnant females on the other hand tend to reproduce with a much higher probability the following year $(73 \%)$. When translated into the commonly used terminology of reproductive cycles, our results show that smooth snake reproduction cycles in Norway are between biennial and triennial, which is in accordance with expectations by Andrén and Nilson (1976) 

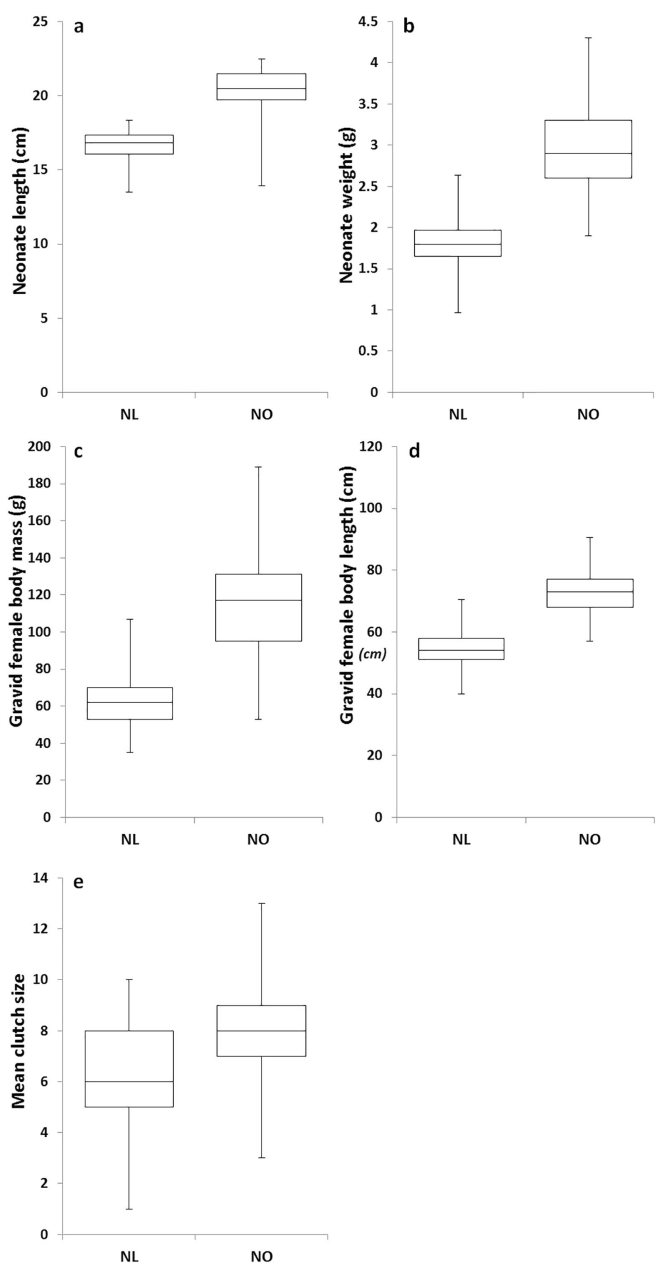

Figure 4. Neonate length (a), neonate weight (b), pregnant female total body length (c), pregnant female body mass (d) and mean clutch size (e) of pregnant female smooth snakes Coronella austriaca and neonates in The Netherlands (NL) and Norway (NO). Boxplots showing (from top to bottom) maximum, 75th percentile, median, 25th percentile and minimum values.

and Sørensen (2014). Based on our markrecapture analysis we can estimate the chance that a reproductive female also reproduces the following year at $15 \%$ (i.e., 'annual reproduction), that she skips a year at $0.85 \times 0.73=$ $62 \%$ (i.e., 'biennial reproduction') and $0.85 \times$ $0.27 \times 0.73=16 \%$ for 'triennial reproduction'.

Coronella austriaca occurs in Norway along the Southern coastline in a relatively narrow region. Norwegian smooth snakes are found at the edge of the distribution of species and as a consequence need to adapt to harsher conditions (Rehm et al., 2015). The difference in reproductive frequency between Dutch and Norwegian smooth snakes may also be explained by difference in length of season, habitat use or relative investment per reproduction (Ibargüengoytía et al., 2008). Differences in (adult and neonate) size, prey availability and litter size may add to this as well (Uller and Olsson, 2010).

Norwegian smooth snakes are active from late April/beginning of May until the end of September (Sørensen, 2014). A short annual activity season and frequent periods of suboptimal temperatures represent constraints to both growth and accumulation of resources needed for reproduction.

The warm and dry habitats used by reproducing females (Sørensen, 2014) are relatively low in biological production and in number of prey animals. It seems that the species adapts to this habitat in a number of ways, and being forced to a low reproduction rate may be the result of this. According to Sørensen (2014) sexual maturity is reached at about five years in Norway, whereas it is reached at four years in more southern regions (Reading, 2004b). Most reproducing females found in Norway are larger and heavier compared to the individuals from De Peel. Apparently, this species follows Bergman's rule (Zamora-Camacho et al., 2014), which is not common in squamates as snake species most often follow a converse Bergman's rule (Ashton and Feldman, 2003). Other snake species, however, seem to actually follow Bergman's rule, such as the congeneric Coronella girondica (Vacher and Geniez, 2010). Bergmann's rule states that in wide-ranging species populations occurring at higher latitudes display a larger body size (Bergmann, 1847; Ashton and Feldman, 2003).

The slopes that constitute large parts of the Norwegian habitats as well as the rocky substrate provide the basking snakes with sufficient thermal energy (i.e., by thigmothermy as well as heliothermy) to enable the embryos to develop or to allow the animals to increase in size. This 
is known as the Temperature Size Rule (Atkinson, 1994); the postponed onset of reproductive activity in Norway with on average one year compared to the Netherlands is apparently used for body growth. As stated by Luiselli et al. (1996), an increase in body size and body mass tends to lead to an increase in reproductive output. This in turn seems to be a more optimal adaptation and may aid the smooth snakes in Norway to survive under more extreme conditions.

Dupoué et al. (2017) addressed the Metabolic Rate (MR) in different species of snakes and found that metabolic rate is higher in colder climates. A larger body size, as found compared to more southern populations of smooth snakes could aid in reaching activity temperature levels more easily. Metabolic rate was also found to differ intraspecifically by Lardies et al. (2004).

Low average temperatures in smooth snake habitats in Norway lead to an extended period of relatively slow growth, delayed development and maturation and less frequent reproduction in this poikilothermic species. This in contrast to The Netherlands where, because of higher temperatures, snakes reach sexual maturity earlier and at a smaller body size.

Norwegian female smooth snakes produce litters consisting of more, larger and heavier neonates (mean total body length $20.6 \mathrm{~cm}$, mean body mass $3 \mathrm{~g}$ ) thus compensating for this postponed and low reproduction rate (table 3). Heavier neonates may increase survival especially in the first year(s) and larger clutch size may compensate for starting reproduction at a higher age in Norway (Dupoué and Lourdais, 2014).

Relative investment (mean clutch-mass per mean female body mass) of pregnant females in Norway (0.17) and The Netherlands (0.2) differs to some extent. Norwegian snakes presumably will reproduce during a much higher number of years than Dutch smooth snakes do since reproduction does occur less often than in The Netherlands. Northern smooth snakes may differ in thermoregulation strategy compare to animals from The Netherlands, as was found by Lourdais et al. (2013) when comparing the common adder (Vipera berus) to the asp viper (Vipera aspis).

Life expectancy should supposedly be relatively high in Norway. An indication of this is a record of a female snake that was observed reproducing in 1993 for the first time and last observed as a pregnant individual in 2009 in Norway. When caught in 1993 she had a total body length of $79 \mathrm{~cm}$ indicating an age of at least 10 years (Sørensen, 2014). This means that this specimen was at least 26 years by the time of the second capture in 2009. Similar findings for were recorded for the black rat snake (Elaphe obsoleta) by Blouin-Demers et al. (2002). Reading (2004b) estimated the maximum age in southern England for female smooth snakes to be 16 years and 17 years for males. Life expectancy was, in accordance with our findings, also found to be related to larger body size and the onset of reproduction at a later age for a variety of species (Speakman, 2005) including squamates (Scharf et al., 2015).

Clutch size and neonate size are all significantly larger in Norway, as are (total) body length of neonates. Larger clutch size in conjunction with larger total body length and higher body mass and as a consequence a higher survival rate during hibernation may render neonates with better chances to survive during the first years of life, thereby compensating for a lower frequency of reproductive activity in Norwegian female smooth snakes.

With respect to diet, prey size may in particular be a crucial factor determining what food sources are available for neonates and as a consequence their chances of survival. Other food sources than reptiles and small mammals may be of importance then and this aspect of the diet is currently studied in The Netherlands, specifically concerning food sources for juveniles (Reading and Jofré, 2013, 2020; Brown et al., 2014; Völkl et al., 2017). 
In summary, we applied multi-state capturemark-recapture analyses to quantify the reproductive rate in $C$. austriaca more accurately. Moreover, we demonstrated a clear difference in reproductive rate between Norway and The Netherlands, with only $15 \%$ of pregnant females reproducing again in the following year in Norway versus $93 \%$ in The Netherlands. Furthermore, we linked this difference to the length of the season and characteristics of the biotopes. During a shorter reproductive season in Norway individual females tend to grow larger and start reproduction at a higher age. Litter size and juvenile total body length and weight are also significantly higher in Norwegian smooth snakes.

Populations at the edge of their geographic distribution display the most extreme features in the sense of phenotypic adaptations in response to environmental parameters. In the light of climate change and the sixth mass extinction hypothesis the speed with which adaptation takes place is a key feature to survival for many species (Hoffmann and Sgró, 2011; Geyle et al., 2020; Rutschmann et al., 2020).

Genetic diversity in Norway is supposedly limited (although no genetic data are available) and numbers of individuals found within populations are relatively small. Coronella austriaca seems to be an excellent species to further study genetic diversity and phenotypic adaptation, so future research should address this topic.

Acknowledgements. We thank all students involved in collecting and processing data over the years. The Netherlands Organisation for Scientific Research issued the Doctoral PhD-grant for teachers (number 023.002.012) and provided funding for implementation of the research program.

\section{References}

Andrén, C., Nilson, G. (1976): Hasselsnoken (Coronella austriaca) - en utrotningshotat ormart! Fauna Flora 71: 61-76.

Ashton, K.G., Feldman, C.R. (2003): Bergmann's rule in nonavian reptiles turtles follow it, lizards and snakes reverse it. Evolution 57: 1151-1163.
Atkinson, D. (1994): Temperature and organism size - a biological law for ectotherms? Adv. Ecol. Res. 25: 1-58.

Beebee, T.J.C. (2008): Buccal swabbing as a source of DNA from squamate reptiles. Conserv. Genet. 9: 1087-1088.

Bergmann, C. (1847): Ueber die Verhältnisse der Wärmeökonomie der Thiere zu ihrer Grösse. Göttinger Studien 1: 595-708.

Blouin-Demers, G., Prior, K.A., Weatherhead, P.J. (2002): Comparative demography of black rat snakes (Elaphe obsoleta) in Ontario and Maryland. J. Zool. 256: 1-10.

Bonnet, X., Naulleau, G. (1996): Catchability in snakes: consequences for estimates of breeding frequency. Can. J. Zool. 74: 233-239.

Brischoux, F., Dupoué, A., Lourdais, O., Angelier, F. (2016): Effects of mild wintering conditions on body mass and corticosterone levels in a temperate reptile, the aspic viper (Vipera aspis). Comparat. Biochem. Physiol. A 192: 52-56.

Brown, D.S., Ebenezer, K.L., Symondson, W.O.C. (2014): Molecular analysis of the diets of snakes: changes in prey exploitation during development of the rare smooth snake Coronella austriaca. Mol. Ecol. 23: 3734-3743.

Buckley, L.B., Hurlbert, A.H., Jetz, W. (2012): Broad-scale ecological implications of ectothermy and endothermy in changing environments. Glob. Ecol. Biogeogr. 21: 873-885.

Capula, M., Luiselli, L., Rugiero, L. (1995): Ecological correlates of reproductive mode in reproductively bimodal snakes of the genus Coronella. Vie Milieu 45: 167-175.

Cooch, E.G., White, G.C. (2019): Program MARK, a Gentle Introduction, 19th Edition. http://www.phidot.org/ software/mark/docs/book/.

Creemers, R.C.M., van Delft, J.J.C.W. (2009): De amfibieën en reptielen van Nederland. - Nederlandse Fauna 9. Nationaal Natuurhistorisch Museum Naturalis, European Invertebrate Survey - Nederland, Leiden.

Duguy, R. (1961): Le cycle annuele d'activite de Coronella austriaca Laur.; d'aprés les observations manuscrites indites de Raymond Rollinat. Terre Vie 15: 401-435. In: Luiselli, L., Capula, M., Shine, R. (1996): Reproductive output, costs of reproduction, and ecology of the smooth snake, Coronella austriaca, in the eastern Italian Alps. Oecologia 106: 100-110.

Dupoué, A., Lourdais, O. (2014): Relative reproductive effort drives metabolic changes and maternal emaciation during pregnancy in a viviparous snake. J. Zool. 293: 49-56.

Fretey, J. (1975): Guide des Reptiles et Batraciens de France. Hatier, Paris.

Geyle, H.M., Tingley, R., Amey, A.P., Cogger, H., Couper, P.J., Cowan, M., et al. (2020): Reptiles on the brink: identifying the Australian terrestrial snake and lizard species most at risk of extinction. Pacif. Conserv. Biol. DOI:10.1071/PC20033.

Goddard, P., Spellerberg, I.F. (1980): Reproduction as a factor in the conservation of Coronella austriaca Laur. in Southern England. B. D'Ecol. 11: 535-541.

Hileman, E.T., King, R.B., Adamski, J.M., Anton, T.G., Bailey, R.L., Baker, S.J., et al. (2017): Climatic and geographic predictors of life history variation in Eastern Downloaded from Brill.com04/26/2023 05:23:11AM via free access 
Massasauga (Sistrurus catenatus): a range-wide synthesis. PLoS ONE 12: e0172011.

Hoffmann, A.A., Sgró, C.M. (2011): Climate change and evolutionary adaptation. Nature 470: 479-485.

Ibargüengoytía, N.R., Acosta, J.C., Boretto, J.M., Villavicencio, H.J., Marinero, J.A., Krenz, J.D. (2008): Field thermal biology in Phymaturus lizards. Comparisons from the Andes to the Patagonian steppe in Argentina. J. Arid Environ. 72: 1620-1630.

Joe, M., Pollock, K.H. (2002): Separation of survival and movement rates in multi-state tag-return and capturerecapture models. J. Appl. Stat. 29: 373-384.

Jolly, J.M. (1965): Explicit estimates from capturerecapture data with both death and immigrationstochastic model. Biometrika 52: 225-247.

Köntopp, B. (2010): Habitatwahl und Populationsökologie der Schlingnatter (Coronella austriaca Laurenti, 1768) in einem anthropogen beeinflussten Hochmoor Schleswig-Holsteins. Faunistisch-ökologische Mitteilungen 9 (3/4): 77-109.

Lardies, M.A., Bacigalupe, L.D., Bozinovic, F. (2004): Testing the metabolic cold adaptation hypothesis: an intraspecific latitudinal comparisonin the common woodlouse. Evol. Ecol. Res. 6: 567-578.

Lebreton, J.D., Pradel, R. (2002): Multistate recapture models: modelling incomplete individual histories. J. Appl. Stat. 29: 353-369.

Lourdais, O., Bonnet, X., Shine, R., Denardo, D., Naulleau, G., Guillon, M. (2002): Capital-breeding and reproductive effort in a variable environment: a longitudinal study of a viviparous snake. J. Anim. Ecol. 71: 470-479.

Lourdais, O., Guillon, M., DeNardo, D., Blouin-Demers, G. (2013): Cold climate specialization adaptive covariation between metabolic rate and thermoregulation in pregnant vipers. Physiol. Behav. 119: 149-155.

Luiselli, L., Capula, M., Shine, R. (1996): Reproductive output, costs of reproduction, and ecology of the smooth snake, Coronella austriaca, in the eastern Italian Alps. Oecologia 106: 100-110.

Monney, J.C., Luiselli, L., Capula, M. (1995): Notes on the natural history of the smooth snake, Coronella austri$a c a$, in the Swiss Alps. Brit. Herpetol. Soc. B. 54: 21-27.

Naulleau, G. (1987): Les serpents de France. Rev. Franc. d'Herpetol. Aquariol. 11 (3-4): 1-56.

Norwegian Meteorological Institute (Meteorologisk institutt), statistics. Available at https://www.yr.no/place/ Norway/Oslo/Oslo/Oslo_(Blindern)_observation_site/ statistics.html/ (Downloaded on 2 November 2018).

Peel, M.C., Finlayson, B.L., McMahon, T.A. (2007): Updated world map of the Köppen-Geiger climate classification. Hydrol. Earth Syst. Sci. 11: 1633-1644.

Prival, D.B., Schroff, M.J. (2012): A 13-year study of a northern population of twin-spotted rattlesnakes (Crotalus pricei): growth, reproduction, survival, and conservation. Herpetol. Monogr. 26: 1-18.

Reading, C.J. (2004a): The influence of body condition and prey availability on female breeding success in the smooth snake (Coronella austriaca Laurenti). J. Zool. 264: 61-67.
Reading, C.J. (2004b): Age, growth and sex determination in a population of smooth snakes, Coronella austriaca in southern England. Amphibia-Reptilia 25: 137-150.

Reading, C.J. (2012): Ranging behaviour and home range size of smooth snakes inhabiting lowland heath in southern England. Herpetol. J. 22: 241-247.

Reading, C.J., Jofré, G. (2013): Diet composition changes correlated with body size in the smooth snake, Coronella austriaca, inhabiting lowland heath in southern England. Amphibia-Reptilia 34: 463-470.

Reading, C., Jofré, G. (2020): Smooth snake population decline and its link with prey availability. AmphibiaReptilia 41: 43-48.

Rehm, E.M., Olivas, P., Stroud, J., Feeley, K.J. (2015): Losing your edge. Climate change and the conservation value of range-edge populations. Ecol. Evol. 5: 43154326.

Royal Netherlands Meteorological Institute (KNMI), daily temperatures, available at https://www.knmi.nl/ nederland-nu/klimatologie/daggegevens/ (Downloaded on 2 November 2018).

Rutschmann, A., Rozen-Rechels, D., Dupoué, A., Blaimont, P., de Villemereuil, P., Miles, D.B., Richard, M., Clobert, J. (2020): Climate dependent heating efficiency in the common lizard. Ecol. Evol. 10: 8007-8017.

Sauer, A. (1994): Methode zur Identifizierung der Schlingnatter (Coronella austriaca). Salamandra 30: 43-47.

Scharf, I., Feldman, A., Novosolov, M., Pincheira-Donoso, D., Das, I., Böhm, M., Uetz, P., Torres-Carvajal, O., Bauer, A., Roll, U., Meiri, S. (2015): Late bloomers and baby boomers: ecological drivers of longevity in squamates and the tuatara. Glob. Ecol. Biogeogr. 24: 396-405.

Schwarz, C.J., Arnason, A.N. (1996): A general methodology for the analysis of capture-recapture experiments in open populations. Biometrics 52: 860-873.

Seber, G.A.F. (1965): A note on the multiple-recapture census. Biometrika 52: 249-259.

Sørensen, P. (2014): Slettsnoken i Norge. Fauna 66: 110123.

Speakman, J.R. (2005): Body size, energy metabolism and lifespan. J. Exp. Biol. 208: 1717-1730.

Stahlschmidt, Z.R., Lourdais, O., Lorioux, S., Butler, M.W., Davis, J.R., Salin, K., Voituron, Y., DeNardo, D.F. (2013): Morphological and physiological changes during reproduction and their relationships to reproductive performance in a capital breeder. Physiol. Biochem. Zool. 86: 398-409.

Strijbosch, H., van Gelder, J. (1993): Ökologie und Biologie der Schlingnatter, Coronella austriaca Laurenti, 1768 in den Niederlanden. Mertensiella 3: 39-58.

Uller, T., Olsson, M. (2010): Offspring size and timing of hatching determine survival. Oecologia 162: 663-671.

Vacher, J.P., Geniez, M. (2010): Les reptiles de France, Belgique, Luxembourg et Suisse. Biotope. Mèxe y Muséum national d'Historie naturelle, París.

Verberk, W.C.E.P., Atkinson, D., Hoefnagel, K.N., Hirst, A.G., Horne, C.R., Siepel, H. (2020): Shrinking body sizes in response to warming: explanations for the Downloaded from Brill.com04/26/2023 05:23:11AM via free access 
temperature-size rule with special emphasis on the role of oxygen. Biol. Rev. DOI:10.1111/brv.12653.

Völkl, W., Käsewieter, D. (2003): Die Schlingnatter: ein heimlicher Jäger, Beiheft der Zeitschrift für Feldherpetologie. Laurenti, Bielefeld.

Völkl, W., Käsewieter, D., Alfermann, D., Schulte, U., Thiesmeier, B. (2017): Die Schlingnatter: eine heimliche Jägerin, Beiheft der Zeitschrift für Feldherpetologie 6 . Laurenti, Bielefeld.
Zamora-Camacho, F.J., Reguera, S., Moreno-Rueda, G. (2014): Bergmann's rule rules body size in an ectotherm: heat conservation in a lizard along a 2200-metre elevational gradient. J. Evol. Biol. 27: 2820-2828.

Submitted: August 2, 2020. Final revision received: November 17, 2020. Accepted: December 7, 2020. Associate Editor: Sylvain Ursenbacher. 